\title{
Framework for Externalization of Tacit Knowledge in Participatory Agricultural Research in Ethiopia: The Case of Farmers Research Group (FRG)
}

Getahun Semeon Weldemariam St. Mary's University, Ethiopia getahunsemeon@gmail.com

\author{
Monica J. Garfield \\ Bentley University, USA \\ mgarfield@bentley.edu
}

\begin{abstract}
The externalization of tacit knowledge is an important phase for knowledge creation, diffusion \& utilization. The purpose of this study is to explore how different forms of tacit knowledge are externalized by taking a participatory agricultural research group as a case study for the surfacing, codifying and transferring of tacit knowledge. We conducted a qualitative case study that used semi-structured interviews, focus group discussions, observation and document analysis. The study revealed that the dominant forms of tacit knowledge externalized in this participatory agricultural research group fall under a low degree of tacitness (practical skills, lived experiences, rules-ofthumb and expertise) and a medium degree of tacitness (judgments, insights, practical intelligence and indigenous knowledge). Tacit knowledge externalization mechanisms identified include metaphor, storytelling, dialogue, apprenticeship or mentoring, experimentation and evaluation, observation, learning by doing, lessons learnt, modeling technique, localization and on-farm demonstration. A tacit knowledge externalization framework is proposed for the study context.
\end{abstract}

\section{Introduction}

Ethiopian agriculture is the leading sector in the economy in terms of GDP (40\%), employment opportunity (70\%), foreign exchange earnings $(80 \%)$, providing food for the growing population and raw material for domestic industry [9]. It plays a key role in the industrialization and overall transformation of the broader economy. But the sector is challenged by low productivity of land and labor, natural resource degradation, low use of technologies including improved seeds, fertilizer \& irrigation [9]. Because of these problems the sector has failed to attain food security and is unable to produce sufficient wealth that can serve to support the development of other sectors of the economy.
Therefore, enhancing smallholder productivity through sustainable agricultural innovation is central to Ethiopia's development endeavor.

In today's economy, knowledge is the most valuable resource to develop new technology and new products, both of which as necessary to increase efficiency of processes and quality of products and to sustain competitive advantage [7]. Knowledge as a critical resource serves not only in the high tech industries and the service sector but it is also a critical input for enhancing sustainable agricultural development and food security [19]. Such knowledge could be explicit and reside in documents, manuals, reports, etc. or tacit which is embedded in the human mind, non-codified, difficult to articulate and subconsciously understood and applied [23] [1]. A great deal of knowledge that is important to innovation or improvement of a given process or product is tacit knowledge [4]. It takes the form of experience, know-how, skills, expertise, best practices, values, ideas, feelings, emotions, insights, judgments, beliefs and cognition. Tacit knowledge plays a dominant role in agricultural research, and extension and advisory services which are the most knowledge-intensive forms of agricultural innovation systems [12]. It provides dynamic responses to context-specific problems [32] and serves as a critical vehicle to successfully transfer best practices within communities [11]. One of the central dynamics of knowledge creation is externalization or the transformation of knowledge from tacit to explicit [24] [13].

The Ethiopian government acknowledged that smallholder farmers and pastoralists are empowered with tacit knowledge needed to transition from a traditional subsistence orientation to one that is market focused and more commercialized. That's why smallholder farmers, who account for the vast majority of agricultural production, are considered to be the key partners in the implementation of transformation agenda of the Ethiopian government in its second growth and transformation plan (GTP II). The plan clearly emphasizes the need for close consultation with this critical constituency and the leveraging of indigenous knowledge and practices while designing interventions 
in order to ensure that solutions are quickly accepted and easily scaled. The GTP II plan also acknowledged that innovations come from or are enhanced by the local knowledge of smallholder farmers who are constantly testing and refining new ideas. Cognizant of the critical role of smallholder farmers, a participatory agricultural research approach was developed by forming the Farmers Research Group (FRG). Farmers are key partners in the FRG engaging in the research process and taking part in technology development to support the agricultural sector [9]. Innovation in the agricultural sector not only depends on scientific knowledge of agricultural researchers, but also on better visibility of local solutions developed by innovative farmers [26].

Innovativeness in agriculture is highly dependent on the extent to which collective tacit knowledge of agricultural researchers, farmers, extension workers, processors, input providers, local leaders, government officers, etc. is used [30]. The main objective of any knowledge management initiative in this environment should foster the elicitation, capturing and sharing of tacit knowledge of this range of actors. Studying tacit knowledge is both theoretically and practically relevant since it constitutes a significant proportion of the body of knowledge capital [15]. One area that needs further investigation and deeper understanding is the process of externalization of tacit knowledge [29], [18]. Tacit knowledge externalization and diffusion and the potential of various mechanisms for the externalizing of different forms of tacit knowledge is still not fully understood [18], [6]. In addition, the agricultural sector has rarely been the topic of inquiry in research related to tacit knowledge elicitation and most previous studies focused on high tech industries and business organizations [10]. The purpose of this study is therefore, to explore how different forms of tacit knowledge are externalized and transferred in a participatory agricultural research context. The finding of this study will inform the development of a system that ensures wider availability and better use of tacit knowledge in fostering agricultural innovation.

\section{Background Literature}

\subsection{Definition and Taxonomies of Tacit Knowledge}

Tacit knowledge is a form of knowledge embedded in the human mind, unarticulated and tied to the senses, tactile experiences, know-how, skills, insights, intuitions, perceptions, ideas, values, feelings, emotions, beliefs, mental models, or implicit rules of thumb [20][23]. It is also represented as local/contextual and embedded in collective practices [25].
Identifying taxonomies of tacit knowledge are important for the understanding of tacit knowledge and exploring the possibilities of and methods for articulating tacit knowledge into explicit knowledge [20]. The degree of tacitness or the extent to which tacit knowledge can be articulated is taken as a basis for developing various classifications. Tacitness can be represented as an abstraction and the level of abstraction varies from completely abstract to quite concrete. Tacit knowledge has been categorized into three main categories - high, medium and low degrees of tacitness [20]. Under high degree of tacitness intuition, gut-feelings or hunches, beliefs, mental-models, taste and artistic-vision are included. This category of tacit knowledge is the most difficult to share between individuals. For items that display a medium degree of tacitness they include insights, talent, judgment, rules-of-thumb, practical intelligence. These epitomes of tacit knowledge are called imperfectly articulable knowledge [2]. They can be expressed in behavior or in the work outcomes and can appear in more tangible forms. Low degree of tacitness items embraces know-how, skills, experiences, expertise, best practices, improvisation, instinctive reaction and ability. These exemplars of tacit knowledge are related to practical work and they are highly visible for individuals, groups and organizations and can be easily articulated. They are based on principles, rules, and heuristics [22]. Tacit knowledge categorized in the medium and low degree of tacitness can be shared in teams and groups while tacit knowledge categorized as a high degree of tacitness is most often contained by only individuals [20].

\subsection{Externalization of Tacit Knowledge}

Externalization is one of the four modes in a spiral process of knowledge conversion in organizational knowledge creation theory [23]. It refers to the process of converting tacit knowledge into explicit knowledge. Tacit knowledge externalization mechanisms include metaphor, analogy, dialogue, storytelling/narratives (myths and stories), mentoring or apprenticing, hands-on experience, demonstrations, asking individuals the right question on what they do, close observation, cognitive mapping, prototyping and collaborative critical thinking processes mediated by a dialogue [23][5][28]. Externalization also occurs through a series of social interactions or when individual's actions or communications are recursively emphasized, through personal reflection and insight, and through different forms of experiential learning [27]. Tacit knowledge becomes increasingly explicit in the process of uttering, formulating a sentence and capturing it in writing [23]. Shared language, symbolic communication and shared meaning are important to the articulation and use of 
knowledge and innovative vocabulary is required for correctly representing the newly articulated knowledge [17]. Through collective reflection, a shared perception is articulated into words, words are developed into phrases and further crystallized into concepts [16]. In collaborative environments like participatory research groups, actors externalize their tacit knowledge through discussion, reflection, observation, making sense of their findings and codifying what they have learned [21]. Externalization is therefore, considered as an extremely important phase for knowledge creation, diffusion \& utilization [23], [31].

Externalization mechanisms have been mapped to tacit knowledge with various levels of abstraction (degree of tacitness) [6] (see table 1).

\section{Table 1: Mapping mechanisms of externalization to degree of tacitness}

\begin{tabular}{|l|l|}
\hline Degree of Tacitness & $\begin{array}{l}\text { Mechanisms of } \\
\text { Externalization }\end{array}$ \\
\hline $\begin{array}{l}\text { intuition, hunches or gut- } \\
\text { feelings, beliefs and mental } \\
\text { models }\end{array}$ & $\begin{array}{l}\text { observation, mentoring and } \\
\text { apprenticeship }\end{array}$ \\
\hline $\begin{array}{l}\text { insights, talent, judgment, } \\
\text { rules-of-thumb and } \\
\text { practical intelligence }\end{array}$ & $\begin{array}{l}\text { metaphor, analogies, } \\
\text { storytelling, concept } \\
\text { mapping, prototyping, and } \\
\text { brainstorming }\end{array}$ \\
\hline $\begin{array}{l}\text { experience best-practices, } \\
\text { knowhow, skills, } \\
\text { improvisation, instinctive } \\
\text { reaction and ability }\end{array}$ & $\begin{array}{l}\text { expert systems, structured } \\
\text { expert interviews, best } \\
\text { practices, and lessons } \\
\text { learned }\end{array}$ \\
\hline
\end{tabular}

Adopted from [6]

\section{Research Methods}

We used a qualitative research approach in our case study. The focus of our work was farmer research groups (FRGs) in Ethiopia. FRGs are comprised of multidisciplinary research teams, extension workers and groups of farmers who jointly conduct research on selected topics pertaining to farmers' needs. 15 to 20 farmers are included in each FRG. From FRG members five of them are selected as trial farmers who can be directly involved in the research process and provide their plots as trial sites for the new agricultural research put forward by the FRG. Training and field demonstrations are conducted followed by on-farm activities including field experiments, observations, monitoring and evaluation of the tested new techniques. Frequent meetings include such activities as visiting onfarm activities, holding consultative workshops, seminars, and trainings, and performing demonstrations [3]. Agricultural research centers and universities take part in various FRG projects based on their experience. FRG project sites used in this study include Melkasa Agricultural Research Center, Adami Tulu Agricultural Research Center, Holeta Agricultural Research Center, Assosa Agricultural Research Center, Wolaita Sodo University and Mekelle University.

By using a qualitative case study approach we were able to collect rich and contextual data as well as detailed situated knowledge [8]. It enabled us to conduct a deep investigation into the social phenomena of tacit knowledge externalization in a participatory research environment that involves complex social interactions among multiple actors. Data was collected through indepth semi-structured interviews, observation, focus group discussions, and document analysis. We used a purposive, non-random sampling technique and snowballing in order to pick appropriate respondents for the in-depth interview and focus group discussions. A total of 14 multi-disciplinary agricultural researchers and extension agents were involved in the interviews. Two focus groups of 4 farmers each were conducted. The farmers that took part in the focus groups were all taking part of one FRG (Holeta Agricultural Research Center FRG) (see appendix 1 for interview questions and appendix 2 focus group questions)

We observed one field visit conducted on one FRG project at Mariachare Kebele in Wolaita Sodo area. During this site visit we observed the full FRG meeting and took field notes. To enhance our background knowledge and understanding of the context in which we were researching, we collected documents such as reports, manuals, and guidelines provided to us from the FRG project sites. Data was analyzed through thematic coding and thematic analysis which resulted in identifying unique patterns representing different taxonomies of tacit knowledge and the mechanisms used for its articulation and sharing. NVivo 10 (a qualitative data analysis tool) was used for coding purposes and for extracting the theoretical concepts.

\section{Results}

Our key findings were focused on understanding what types of tacit knowledge were being externalized and the externalization mechanisms. We will first discuss the different categories of tacit knowledge which we found were being externalized. We will then discuss what mechanisms were being used to share this knowledge.

\subsection{Taxonimes of Tacit Knowledge}

Farmers, as key partners in the participatory research process, provided their own perspectives, experiences and indigenous knowledge to help solve the local 
agricultural problems. Divergent perspectives were also solicited from multidisciplinary research teams, extension agents and other stakeholders involved in the participatory research undertaken by the FRGs. The overall findings indicated that the knowledge shared within the FRGs fell under the category of medium and low degree of tacitness. This is not surprising since agricultural research is "more of applied research and not as conceptual and abstract as basic research" (Agricultural Researcher 08). The following table summarizes empirical evidence that arouse from the data analysis on the taxonomies of tacit knowledge dominantly articulated in the FRG groups. We will discuss these findings in our discussion section.

\section{Table 2: Empirical evidence on taxonomies of degree tacit knowledge}

\begin{tabular}{|c|c|}
\hline $\begin{array}{l}\text { Tacit } \\
\text { Knowledge } \\
\text { Type }\end{array}$ & Empirical Evidence \\
\hline \multicolumn{2}{|c|}{ Low Degree of Tacitness } \\
\hline $\begin{array}{l}\text { Rules-of- } \\
\text { thumb }\end{array}$ & $\begin{array}{l}\text { - "based on their principles } \\
20 \mathrm{~cm} \text { to } 30 \mathrm{~cm} . . . \text { "( Agricu }\end{array}$ \\
\hline \multicolumn{2}{|c|}{ Medium Degree of Tacitness } \\
\hline Insights & $\begin{array}{l}\text { - "An insightful farmer recommended how the fruit should be positioned when it is planted and make it more productive.... After } \\
\text { conducting research scientists proved that the position signify the optimal angle of the sun shine that makes the plant more } \\
\text { productive" (Agricultural Researcher 07) } \\
\text { "....insightful researchers manipulate the existing practices and generate new ways... add additional treatments to come up } \\
\text { with better results..." (Agricultural Researcher } 11 \text { and Agricultural Researcher } 02 \text { ) }\end{array}$ \\
\hline $\begin{array}{l}\text { Indigenous } \\
\text { Knowledge }\end{array}$ & $\begin{array}{l}\text { - “.. A farmer treated sick oxen by piercing its skin and pushing air into the skin ....” (Agricultural Researcher 03) } \\
\text { - "In storage pest management project...farmers mixed grain with pepper to control pest" (Agricultural Researcher 06) } \\
\text { - "In maize project a farmer cut unique weed \& broadcasted it on the plot in order to control termite problem" (Agricultural } \\
\text { Researcher 05) } \\
\text { - "one farmer was using 'shilshallo' or oxen driven inter-row plowing to control weed in an innovative way without affecting } \\
\text { the root of the plant” (Agricultural Researcher 11) }\end{array}$ \\
\hline $\begin{array}{l}\text { Judgmental } \\
\text { Knowledge }\end{array}$ & $\begin{array}{l}\text { - "... After conducting the experiment we (farmers) preferred manual/conventional row-planting technique over machine based } \\
\text { due to its greater precision, space saving, convenience, friendliness to oxen...." (Farmer 02) } \\
\text { "... farmers rejected the use of sand in experiment on seed spreader technology by considering its negative impact on soil } \\
\text { fertility" (Agricultural Researcher 1) }\end{array}$ \\
\hline $\begin{array}{l}\text { Practical } \\
\text { Intelligence }\end{array}$ & $\begin{array}{l}\text { - "...in the evaluation of the productivity of different varieties of maize a farmer was looking at the distance between the stalk } \\
\text { and the cob and he demonstrated that if the distance is wide it is productive while if the cob is very close to the stalk it is less } \\
\text { productive..... gauging productivity level using the angle between the stalk and the cob was a unique measurement technique } \\
\text { which has never been used in the scientific method. ." (Agricultural Researcher 07) } \\
\text { "when farmers evaluated a newly introduced donkey-driven cart developed by the research center they commented that it is } \\
\text { heavy for donkey and need to be redesigned for oxen since they are stronger and have hump to pull the cart. ... they also } \\
\text { suggested that if it is designed for donkey there is a need to use tier rather than metal wheel \& one beam rather than two. Such } \\
\text { innovative inputs from farmers helped us to redesign the cart" (Agricultural Researcher 07) } \\
\text { "In the row planting project the research recommended measuring of the 20cm distance between seeds using rope, drilling } \\
\text { the ground, dropping each seed into the hole and turning over the soil. Farmers found this method highly labor intensive and } \\
\text { time consuming...they introduced innovative ways of maintaining 20cm distance in row planting using adjustable oxen-driven } \\
\text { hoe... it was highly labor \& time saving ..." (Agricultural Researcher 10) } \\
\text { "... farmers reduced 4cm distance between onion seeds into 2cm and achieved more yield through new ways of planting - } \\
\text { zigzagging" (Agricultural Researcher 4) }\end{array}$ \\
\hline
\end{tabular}




\subsection{Mechanisms of Tacit Knowledge Externalization}

Our data revealed that metaphor, storytelling, dialogue, apprenticeship/mentoring, experimentation and evaluation, observation, learning-by-doing, lessons learned, modeling technique, localization and on-farm demonstration were the mechanisms commonly used to externalize tacit knowledge in our FRGs. The following table summarizes empirical evidence corresponding to each mechanism. We will discuss these results further in our discussion section.

\section{Table 3: Tacit knowledge externalization mechanisms}

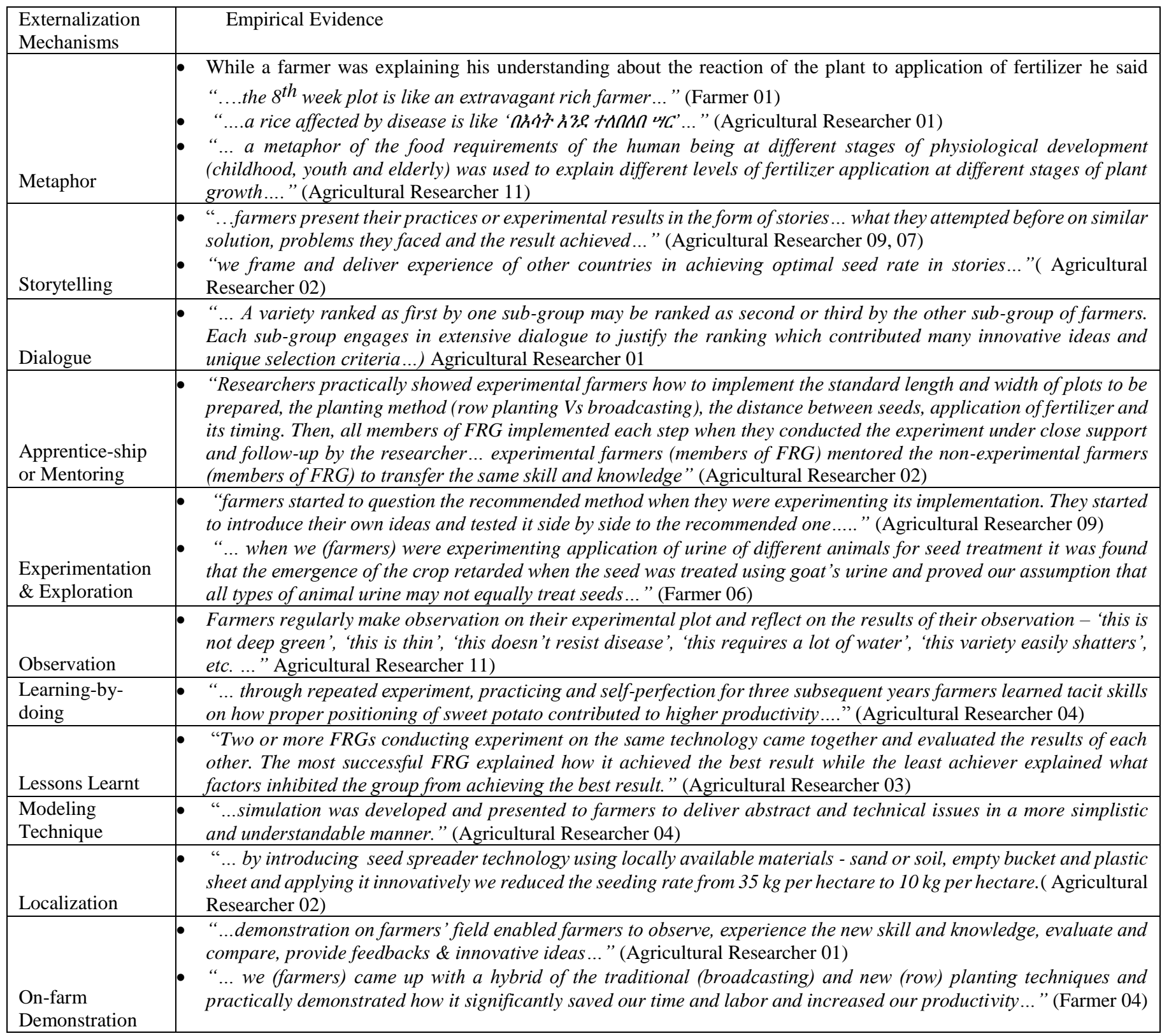




\section{Discussion}

Our study revealed the types of tacit knowledge that have been externalized and shared in our case environment had low and moderate levels of tacit knowledge. This is not surprising given that knowledge that is very high on the tacit dimensional typically is not sharable and frequently resides within a single individual. Our work focused on group interactions and the sharing of knowledge for participatory research in FRGs. Therefore, it was unlikely that knowledge that is high in tacitness would be observed being discussed or surfaced. However, we find it insightful to think about forms of tacit knowledge on a range from being high to low in tacitness. Under this paradigmatic way of understanding the tacitness of knowledge it is clear that some forms of tacit knowledge can be externalized and can be captured and shared within a community. There has been a debate about the ability to externalize tacit knowledge and to capture it. This study shows that in fact you can, but that not all tacit knowledge is amenable to being transformed into more explicit knowledge. The degree of tacitness embedded within the knowledge in which you are trying to convey to others plays a significant role in how successful it can be transferred. Furthermore, we have seen in most large government projects that are aimed at improving the agricultural sector's productivity in Ethiopia knowledge was transferred typically in a uni-directional way moving from research and government agencies to farmers. In the case of FRGs, farmers are becoming a vital part of the growth and sharing of agricultural knowledge in efforts to improve efficiently and capacity in the Ethiopian agricultural sectors.

We found that farmers played a significant role in the articulation and sharing of their tacit knowledge under different degrees of abstraction. Identification of such taxonomies with farmers being key players in the process is essential for designing appropriate methods and systems that support the conversion of agricultural tacit knowledge into the explicit form. The predominance of knowledge with low and medium degrees of abstraction in the participatory agricultural research context confirm that there is a higher possibility of such knowledge to be observed, taught, codified and disaggregated from its context [22].

Secondly, we found that different mechanisms were used by the actors involved in the FRG groups to externalize and share their tacit knowledge. Contrary to prior studies that suggested a one-to-one relationship between knowledge with particular degree of tacitness and the mechanisms used to externalize it, our study signified that one mechanism can be applied to externalize knowledge with different degrees of tacitness. For example, metaphorical expressions were used to represent unarticulated perception of similarity between two things derived from experiences (low degree of tacitness) and articulation of judgmental knowledge (medium degree of tacitness). The same is true with storytelling, apprenticeship and mentoring.

It was found that the process of recurrent experimentation and evaluation on the proposed agricultural technologies and agronomic practices on farmers' plots was the most effective mechanism of externalizing tacit knowledge. This is because it explicates and conveys tacit skills that are inexpressible in words by illuminating what works under specific environments and what doesn't. Furthermore, it allows actors to explore alternatives and identify the best approaches and provide feedback; to question the proposed solutions and introduce their ideas; to develop a hybrid solution consisting of the proposed scientific solution and their localized innovation. Therefore, this mechanism (experimentation and evaluation) allowed the externalization of several forms of knowledge with varying degrees of abstraction. Another unique finding in this study is the identification of the externalization mechanisms from a localization perspective. An example of such an effort is when an FRG group worked to determine critical application timing and optimal mixes to develop effective organic fertilizers from abundantly available local natural leaves.

The following figure (figure 1) represents a proposed framework for tacit knowledge externalization in a collaborative research environment.

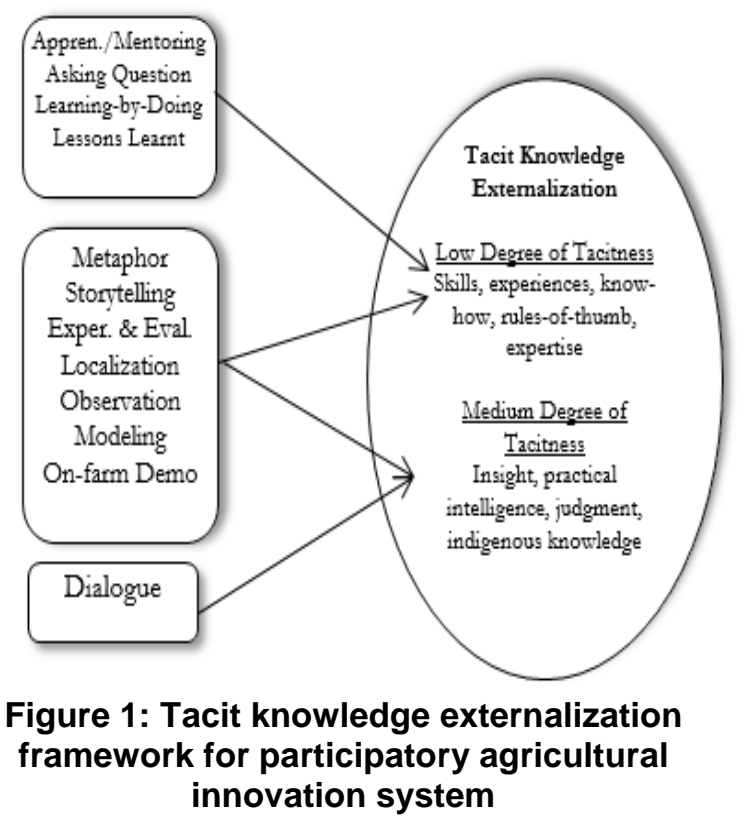




\section{Conclusion}

This study explored how different forms of tacit knowledge are externalized and transferred by taking the participatory agricultural research approach of FRG groups as a case. This study revealed that the dominant forms of tacit knowledge externalized and shared in FRGs fall under medium and low degrees of tacitness. Tacit knowledge with high degrees of tacitness or abstraction were not found to be explicated in this study. Practical skill, lived experiences of farmers, rules-ofthumb and expertise were identified as the dominant forms of tacit knowledge with low degrees of tacitness. In addition, judgments, insights, practical intelligence and indigenous knowledge were identified as the dominant forms of tacit knowledge with medium degrees of tacitness. The study revealed a number of tacit knowledge externalization mechanisms including metaphor, storytelling, dialogue, apprenticeship or mentoring, experimentation and evaluation, observation, learning by doing, lessons learnt, modeling technique, localization and on-farm demonstration. As opposed to prior studies [6] there is no one-to-one relationship between mechanisms of externalization and degree of tacitness. One mechanism may be used for the articulation of tacit knowledge with different degrees of tacitness. Finally, a tacit knowledge externalization framework was proposed for the study context, participatory agricultural research environments.

In terms of contribution to theory, the study provided empirical evidence of tacit knowledge externalization constructs by considering a unique context in the agricultural sector where empirical evidence is limited [14]. The theoretical framework can be a basis for conducting further studies either to empirically test the framework or to investigate issues pertaining to tacit knowledge externalization in different contexts or from different perspectives. Regarding its contribution to practice, the understanding of the types of tacit knowledge used in a multiple stakeholder environment can help in making practical decisions as to how to capture such tacit knowledge in a formal way or foster an environment where it can be shared informally.

\section{Future Work}

The next step in our work will be to extract design principles for developing systems of communication that can support externalization mechanisms and capture tacit knowledge. Design constructs can be extracted to inform practitioners to better understand the features of communication systems and models that can support the tacit knowledge externalization process. Further research can be conducted to replicate our study to examine whether constructs of the framework can be supported in different contexts. In addition, future research can focus on hypothesizing and testing the effects of externalization mechanisms on different forms of tacit knowledge using more objective measures.

\section{References}

[1] M. S. Al-Qdah, and J. Salim, "A conceptual framework for managing tacit knowledge through ICT perspective", Procedia Technology (1), 2013, pp. 1188 - 1194.

[2] V. Ambrosini, \& C. Bowman, , "Tacit knowledge: Some suggestions for Operationalization," Journal of Management Studies, Vol. 38, No.6, 2001, pp. 811-829.

[3] C. Anchala,; A. Deressa,; H. Admasu,; and E. Habte, , "Enhancing Innovations through Farmer Research Groups (FRGs): Basic Concepts and Experience in Other Countries. Farmer Research Group (Frg): Concept And Practices," 29, 2004, pp. 1-130.

[4] B. Büchel, L. Nieminen,; H. Armbruster-Domeyer, and D. Denison, "Managing stakeholders in team-based innovation: The dynamics of knowledge and trust networks", European Journal of Innovation Management. Vol. 16 No. 1, 2013, p. 22-49.

[5] C. Chen, "The knowledge creation process to organizational theories: A macro view of organizationenvironment change", Journal of Organizational Change Management, Vol. 21, No.3, 2008, pp. 259 - 279.

[6] Chennamaneni, A. and Teng, J. T . C., "An integrated framework for effective tacit knowledge transfer", Proceedings of the Seventeenth Americas Conference on Information Systems. Detroit, Michigan. August 4th7th, 2011.

[7] S. Chou, and Y. Chang, "An Empirical Investigation of Knowledge Creation in Electronic Networks of Practice: Social Capital and Theory of Planned Behavior (TPB)," Proceedings of the 41st Hawaii International Conference on System Sciences. IEEE, 2008.

[8] K. M. Eisenhardt, , and M. E. Graebner, "Theory building from cases: Opportunities and challenges," Academy of management journal, Vol. 50, No. 1, 2007, pp. $25-32$

[9] B. Emana, "Evaluation of Impacts of Farmers Research Group Activities in the Rift Valley of Ethiopia," Final Report Addis Ababa, 2009.

[10] I. M. Galindo, "Regional Development through Knowledge Creation in Organic Agriculture," Journal of Knowledge Management, Vol. 11, No. 5, pp. 87 - 97, 2007.

[11] M. B. Greenman, "The contribution of knowledge management systems to inter-organizational learning," SIGMIS-CPR'06, ACM, April 13-15, $2006 .$.

[12] A. Goyal, "ICT in agriculture sourcebook: Connecting smallholders to knowledge, networks, and institutions," World Bank, 2011.

[13] C. Gubbins, S. Corrigan,; T. N. Garavan, C. O. Connor,; D. Leahy, D. Long, and E. Murphy, "Evaluating A Tacit Knowledge Sharing Initiative: A Case Study", European Journal of Training and Development, Vol. 36, No. 8, pp. 827-847.

[14] S.N. Gourlay, "Conceptualizing Knowledge Creation: A Critique of Nonaka's Theory", Journal of Management Studies, Vol. 43 No. 7, 2006, pp. 1415-36. 
[15] M. He, , \& Y. Li, "Exploiting distributed cognition to make tacit knowledge explicating," Journal of Software Engineering and Applications. Vol. 3, No. 03, 2010, pp. 273-279.

[16] T. Hussi,, "Reconfiguring Knowledge Management Combining Intellectual Capital, Intangible Assets and Knowledge Creation", Journal of Knowledge Management, Vol. 8, No. 2, 2004, pp. 36 - 52.

[17] M. Jakubik, , "Experiencing collaborative knowledge creation processes," The Learning Organization, Vol. 15, No. 1, 2008, pp. $5-25$.

[18] H. Mahroeian, , and A. Forozia, "Challenges in managing tacit knowledge: a study on difficulties in diffusion of tacit knowledge in organizations", International Journal of Business and Social Science, 3, no. 19, 2012, pp. 303328.

[19] A. Mangstl, "Emerging issues, priorities and commitments in e-agriculture", Agricultural Information Worldwide, Vol. 1, No. 1, pp.5-6.

[20] R. McAdam, B. Mason, and J. McCrory, "Exploring the dichotomies within the tacit knowledge literature: Towards a process of tacit knowing in organizations", Journal of Knowledge Management, Vol. 11, No. 2, 2007, p. $43-59$.

[21] M. A. McFadyen, and A. A. Cannella, "Social Capital and Knowledge Creation: Diminishing Returns of the Number and Strength of Exchange Relationships", Academy of Management Journal, Vol. 47 No. 5, 2004, pp. 735-746.

[22] D. McIver, C. A. Lengnick-Hall, M. L. Lengnick-Hall, , and I. Ramachandran, , "Integrating knowledge and knowing: A framework for understanding knowledge-inpractice", Human Resource Management Review, Vol. 22, No. 2, 2012, pp. 86-99.

[23] I. Nonaka, "A dynamic theory of organizational knowledge creation", Organization Science. Vol. 5, No. 1,1994 .

[24] I. Nonaka, and H. Takeuchi,. "The knowledge-creating company", New York, Oxford: Oxford University Press, 1995.

[25] F. Oğuz, and A. E. Şengün, "Mystery of the unknown: revisiting tacit knowledge in the organizational literature", Journal of Knowledge Management, Vol. 15, No. 3, 2011, pp. 445-461.

[26] D. Pattanaik, , and J. Chatterjee, "Socio-technical innovation and the role of conversation in a digital ecosystem for agricultural extension services in india", In Digital Ecosystems and Technologies, 2009. DEST'09. 3rd IEEE International Conference on, pp. 709-714. IEEE, 2009.

[27] L. P. Robert, A. R. Dennis, M. K. Ahuja, "Social capital and knowledge integration in digitally enabled teams. Information Systems Research", Vol. 19, No.. 3, 2008, pp. 314-334.

[28] S. Senaratne, and M. Sexton, "Managing construction project change: a knowledge management perspective", Construction Management and Economics, 26, 2008, pp.1303-1311.

[29] M. Sigala, and K. Chalkit, "Improving performance through tacit knowledge externalization and utilization: preliminary findings from greek hotels", International Journal of Productivity and Performance Management, Vol. 56, No. 5/6, 2007, pp. 456-483.

[30] M. M. Tenywa, , K. P. C. Rao, , R. Buruchara, I. Kashaija, , J. D. Majaliwa, , J. B. Tukahirwa, , A. A., Adekunle, et al. "Institutional innovations for building impact-oriented agricultural research, knowledge and development institutions", Learning Publics Journal of Agriculture and Environmental Studies Vol 2 (1), 2011, pp. 24-55.

[31] H. Tsoukas, "A dialogical approach to the creation of new knowledge in organizations. Organization Science", Vol. 20, No. 6, 2009, pp.941-957.

[32] K. H. Vat, , "Towards a learning organization model for PBL: A virtual organizing scenario of knowledge synthesis", In CD-Proceedings of the Seventh Annual Conference of the Southern Association for Information Systems (SAIS2004), 2004, p. 27-28. 


\section{Appendix 1: Key Interview Questions For Agricultural Researchers}

1. Can you tell me a story about one of the most important FRG projects you were involved in?

2. Do you recall any innovative idea/knowledge forwarded by you or your partners that significantly contributed to the solving of a problem? If so,

a. What was that innovative idea/knowledge?

b. How did you or your partner obtain this innovative idea/knowledge?

3. How was the idea/knowledge presented or communicated to other FRG members?

4. Did you observe variation in personal interpretations when new ideas were presented? If so, what mechanisms were used to resolve conflicts and differences in opinion?

5. Had the idea/knowledge been tacit/hidden to you until it was presented in the group session?

6. Did you or your partners face problem while presenting new idea/knowledge? If so,

a. What kind of problem was faced?

b. How did you address such problem?

7. Do you feel that some of your ideas or knowledge has never been fully presented to your partners?

- If so, why?

- What do you think is the best way to present such idea or knowledge?

8. Can you recall any critical incident that you faced in your involvement in FRG project? If yes,

a. How did you and your partners react to this critical incident?

9. According to your experience, was it documented knowledge (manuals, research outputs) or undocumented knowledge (experience, expertise, skill, know-how, etc.) which was most commonly used in participatory research/FRG project?

10. How do members of FRG share their experience, skill, know-how, expertise, etc. to their partners?

11. Is there any practice of documenting individuals' experience, skill, know-how, expertise, indigenous knowledge, etc.? If so,

- How is it documented?

12. Is the knowledge shared in the FRG project easy to comprehensively document in the form of manuals and reports? If so can you give me sample manual or report?

13. What are the major challenges of participatory research (FRG) in terms of sharing experiences, skills, know-how, expertise, indigenous knowledge, etc.?

14. Who else would you recommend for interview in order to further understand the situation?

\section{Appendix 2: Key Focus Group Questions For Farmers}

1. In which FRG project were you involved? How did you become a member?

2. Can you tell me a story about this project?

3. Did you remember any new idea forwarded by members of the research group? What was that?

4. Have you ever contributed new idea? What was that? Was it familiar to other members?

5. How did you present the idea? Was it accepted? If not, why?

6. If your idea was accepted, was it documented in the form of manual, report, best practice?

7. What should be done in order to facilitate the sharing of idea, experience, skill, indigenous knowledge, etc. among the group? 